\title{
Association of Platelet Counts with Outcome of ICU Stay
}

\author{
Maninder Patni', Uday Pratap ${ }^{2}$, Ruchi Sarawgi', Ruchi Gupta ${ }^{1}$ \\ ${ }^{1}$ Assistant Professor, Pacific Medical College, Udaipur, ${ }^{2}$ Assistant Professor, Geetanjali Medical College, Udaipur.
}

\section{Abstract}

Background: Low platelet count is common in intensive care unit (ICU). Thrombocytopenia has also been associated with poor outcome in ICU.1-4 There is sketchy data regarding thrombocytopenia and its effect on outcome from ICUs in India.5 We aimed to study association of platelet counts with outcome of ICU stay. Subjects and Methods: This was a retrospective study. This study was carried out in patients admitted with a diagnosis of sepsis in the medical ICU, Sepsis was defined using the criteria laid down in the surviving sepsis guidelines 2012.6 Data regarding demography (age and sex), probable source of sepsis, platelet count at admission (Plat-adm), lowest platelet count during the ICU stay (Plat-nadir), platelet fall- defined as Plat-adm - Plat-nadir, APACHE-II score and SOFA score at admission were recorded. Outcome parameters were mortality, length of ICU stay and length of hospital stay. Results: During the study period, a total of 87 patients were admitted in the medical ICU. In 29 patients, criteria of sepsis or outcome of ICU stay were not met, and were excluded from the study. Out of the 48 patients included in the study, 35 patients died and 13 patients survived to transfer out from ICU. Age and sex were similar between them. Data was analyzed for associations. In univariate analysis, there was no association between the platelet counts and disease severity scores, except for Plat-nadir exhibiting a weak negative association with SOFA score at admission (Pearson's R: - 0.303, p= 0.036). Mortality was associated with platelet fall, APACHE-II and SOFA scores at admission (Table 2). A unit increase in APACHE-II-adm and SOFA-adm, and an increment of 10,000 in Plat-fall, increased the odds ratio (OR) of mortality by $14 \%$, 33\% and $21 \%$ respectively. Multivariate analysis was carried using logistic regression methodology and none of the aforesaid were associated with mortality. It is notable that platelet fall narrowly missed independent association, $p=0.07$. Conclusion: This study demonstrates that patients with larger fall in platelet counts may be at increased risk of dying. Larger, prospective studies are needed to further clarify the association of platelet count with outcome of ICU stay.

Keywords: ICU (intensive care unit), Patients with sepsis.

Corresponding Author: Dr. Uday Pratap, Assistant Professor, Geetanjali Medical College, Udaipur.

Received: June 2019

Accepted: June 2019

\section{Introduction}

Low platelet count is common in intensive care unit (ICU). Thrombocytopenia has also been associated with poor outcome in ICU. ${ }^{[1-4]}$ There is sketchy data regarding thrombocytopenia and its effect on outcome from ICUs in India. ${ }^{[5]}$ We aimed to study association of platelet counts with outcome of ICU stay.

\section{Subjects and Methods}

\begin{tabular}{|l|l|l|l|}
\hline Table 1: Analysis of demographic data \\
\hline $\begin{array}{l}\text { Independent } \\
\text { Variables }\end{array}$ & $\begin{array}{l}\text { Transferred } \\
(\mathbf{n = 1 3})\end{array}$ & $\begin{array}{l}\text { Died } \\
(\mathbf{n}=\mathbf{3 5})\end{array}$ & P-value \\
\hline Age (Mean in years) & 58 & 59 & $0.931 \mathrm{~A}$ \\
\hline $\begin{array}{l}\text { Male (n, \% of } \\
\text { outcome) }\end{array}$ & $9(69.2)$ & $23(65.7)$ & $1 \mathrm{~B}$ \\
\hline
\end{tabular}

A Independent Samples T-Test

B Fisher's Exact Test

This was a retrospective study. This study was carried out in patients admitted with a diagnosis of sepsis in the medical ICU, between 15 April 2018 till 15 October 2018 after approval from the ethical committee of our institution. Sepsis was defined using the criteria laid down in the surviving sepsis guidelines 2012.6 Data regarding demography (age and sex), probable source of sepsis, platelet count at admission (Plat-adm), lowest platelet count during the ICU stay (Plat-nadir), platelet fall- defined as Plat-adm - Platnadir, APACHE-II score and SOFA score at admission were recorded.

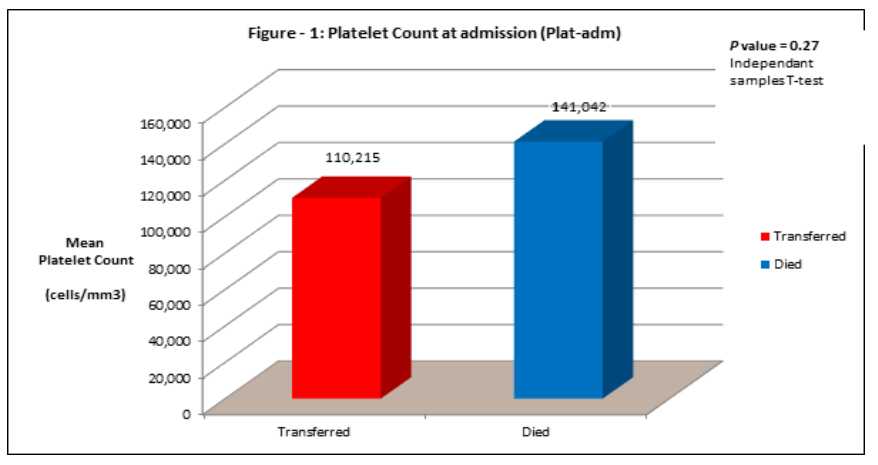

Outcome parameters were mortality, length of ICU stay and length of hospital stay. In our study survival was considered 
if the patient was transferred out of ICU. The type of admission was recorded as place from where patient came into the ICU- whether from other hospital, from hospital floor, from home, or from hospital operation room. Thrombocytopenia was defined as platelet count $<150,000$ cells/mm3. Data was described using appropriate statistical and graphical methods. Univariate analysis was carried out and for hypothesis testing and $\mathrm{p}$ value $<0.05$ was deemed significant. Multivariate analysis was carried out using logistic regression analysis.
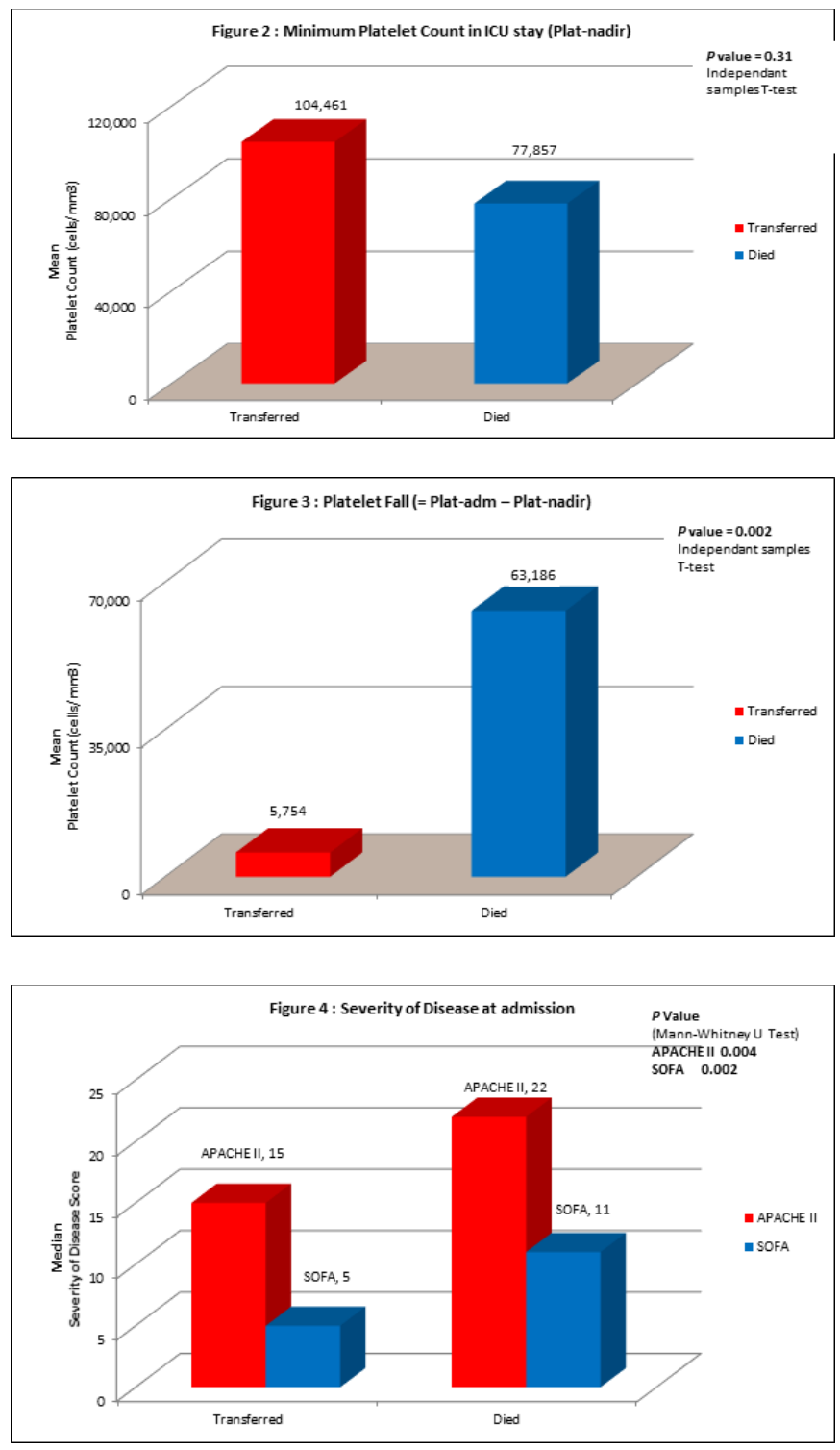

\begin{tabular}{|c|c|c|c|}
\hline $\begin{array}{l}\text { Independent } \\
\text { Variables }\end{array}$ & $\begin{array}{l}\text { Crude OR } \\
\text { for } \\
\text { mortality } \\
(95 \% \text { CI })\end{array}$ & $\begin{array}{l}\text { P-value A } \\
\text { Univariate }\end{array}$ & $\begin{array}{l}\text { P-value B } \\
\text { Multivariate }\end{array}$ \\
\hline Plat-fall & $\begin{array}{l}1.21(1.02- \\
1.44) \mathrm{C}\end{array}$ & $0.03 \mathrm{C}$ & $0.07 \mathrm{C}$ \\
\hline $\begin{array}{l}\text { APACHE-II- } \\
\text { adm }\end{array}$ & $\begin{array}{l}1.14(1.03- \\
1.25)\end{array}$ & 0.01 & 0.32 \\
\hline SOFA-adm & $\begin{array}{l}1.33(1.1- \\
1.61)\end{array}$ & 0.004 & 0.86 \\
\hline
\end{tabular}

A Crude OR for mortality

B Logistic regression for mortality

C for per 10,000 platelets/dL
Results

During the study period, a total of 87 patients were admitted in the medical ICU. In 29 patients, criteria of sepsis or outcome of ICU stay were not met, and were excluded from the study. Out of the 48 patients included in the study, 22 $(45.8 \%)$ came from other hospital to our hospital, $9(18.8 \%)$ came from our hospital floor, 14 (29.2\%) came straight from home and $3(6.3 \%)$ came from our hospital operation room to our ICU. Admission type was neither associated with platelet counts, nor with outcome measures, hence did not confound results. Out of 48 patients included in the study, source of sepsis was deemed as neurological in $5(10.4 \%)$, cardiac in 5 $(10.4 \%)$, respiratory in $22(45.8 \%)$, gastro-intestinal in 15 $(31.3 \%)$, genitourinary in $10(20.8 \%)$, tropical disease in 3 $(6.3 \%)$, hematological in $3(6.3 \%)$, skin in $1(2.1 \%)$, musculoskeletal in $2(4.2 \%)$, poisoning $1(2.1 \%)$, and unknown in $3(6.3 \%)$. Subgroup analysis was not done due to paucity of numbers in respective classes. At admission, 33 $(68.8 \%)$ of 48 patients had thrombocytopenia and during the ICU stay total $37(77.1 \%)$ of 48 developed thrombocytopenia.

In our study, 35 patients died and 13 patients survived to transfer out from ICU. Age and sex were similar between them [Table 1]. For the patients who survived and those who died- mean ( \pm standard deviation $(S D)$ ) platelet count at admission was 110,215 ( \pm 68,954) and 141,042 $( \pm 117,033)$ respectively [Figure 1], mean $( \pm$ SD) platelet nadir was $1,04,461( \pm 71,571)$ and 77,857 $( \pm 82,336)$ respectively (Figure 2$)$, mean $( \pm$ SD) fall in platelet count i.e. difference between platelet counts at admission and nadir, was 7,446 $( \pm$ $39,260)$ and 63,186 $( \pm 81,082)$ respectively (Figure 3$)$, mean ( \pm SD) APACHE-II score at admission $15( \pm 6)$ and 22 ( \pm $10)$ respectively (Figure 4$)$, mean $( \pm$ SD) SOFA score was 5 $( \pm 4)$ and $11( \pm 4)$ respectively (Figure 4), median (range) LoS-ICU was 5 (15) and 7 (57) respectively, median (range) LoS-hosp was 10 (33) and 9 (71) respectively. LoS-ICU and LoS-hosp were neither associated with the platelet counts nor the severity scores.

Data was analyzed for associations. In univariate analysis, there was no association between the platelet counts and disease severity scores, except for Plat-nadir exhibiting a weak negative association with SOFA score at admission (Pearson's R: - 0.303, $\mathrm{p}=0.036$ ). Mortality was associated with platelet fall, APACHE-II and SOFA scores at admission [Table 2]. A unit increase in APACHE-II-adm and SOFAadm, and an increment of 10,000 in Plat-fall, increased the odds ratio (OR) of mortality by $14 \%, 33 \%$ and $21 \%$ respectively. Multivariate analysis was carried using logistic regression methodology and none of the aforesaid were associated with mortality. It is notable that platelet fall narrowly missed independent association, $\mathrm{p}=0.07$.

\section{Discussion}

Reported incidence of thrombocytopenia in ICU is 15$58 \% .{ }^{[1-5]}$ In our study, $77.1 \%$ patients developed thrombocytopenia sometime during their ICU stay. The main causes and mechanisms of thrombocytopenia in ICU settings are hemodilution, increased consumption (after trauma, 
bleeding, immune mediated, disseminated intravascular coagulation), decreased platelet production and increased platelet sequestration. ${ }^{[7]}$ Severe sepsis and other critical conditions are associated with activation of primary (platelet response) and secondary hemostasis (soluble coagulation factors). ${ }^{[8]}$

Thrombocytopenia in the critically ill patients is a marker of the severity of illness. ${ }^{[8,9]}$ Most critically ill patients with thrombocytopenia also have higher Multi Organ Dysfunction Syndrome(MODS), Simplified Acute Physiology Score (SAPS), Acute Physiology And Chronic Health Evaluation (APACHE) scores, ${ }^{[10,11]}$ Thrombocytopenia has been found to be predictive of prolonged ICU stay. Patients with thrombocytopenia had mortality rate $31-46 \%$ and $16-20 \%$ in non thrombocytopenic patients. ${ }^{[12-15]}$ The decline in platelet count correlated better with a poor outcome than the absolute platelet nadir. ${ }^{[16-18]}$ Platelet counts are related to severity of illness may be explained in the important role of platelets in host defense action against infection and inflammation.

Our study carries certain weaknesses. Ours is a retrospective study and prospective studies are better in assessing causality. The sample size of our study is small in comparison to the other studies done on this topic. Hence, subgroup analysis by source of sepsis was not done. Also most of our patients had medical problems and the number of surgical patients was less.

\section{Conclusion}

In conclusion, this study demonstrates that patients with larger fall in platelet counts may be at increased risk of dying. Larger, prospective studies are needed to further clarify the association of platelet count with outcome of ICU stay.

Abbreviations: ICU (intensive care unit), Plat-adm (platelet count at admission),Plat-nadir (lowest platelet count during the ICU stay), platelet fall- defined as Plat-adm - Plat-nadir, Multi Organ Dysfunction Syndrome(MODS), Simplified Acute Physiology Score (SAPS), Acute Physiology And Chronic Health Evaluation (APACHE) scores, sequential organ failure assessment score (SOFA score),

\section{References}

1. Baughman RP, Lower EF, Flessa HC, et al. Thrombocytopenia in the intensive care unit. Chest 1993;104:1243-1247

2. Kinasewitz GT, Yan SB, Basson B, et al. Universal changes in biomarkers of coagulation and inflammation occur in patients with severe sepsis, regardless of causative micro-organism. Crit Care 2004; 8:R82-R90

3. Vanderschueren S, De Weerdt A, Malbrain M, et al. Thrombocytopenia and prognosis in intensive care. Crit Care Med 2000;28:18711876.

4. Stephan F, Hollande J, Richard O, et al. Thrombocytopenia in a surgical ICU. Chest Am SocHematolEduc Program 2010;2010:135-43.

5. Venkata et al. Thrombocytopenia in adult patients with sepsis: incidence, risk factors and its association with clinical outcome. J Intensive Care 2013.

6. Dellinger RP, Levy MM et al. Surviving sepsis campaign: International guidelines for management of sepsis and septic shock: 2012. Crit Care Med. 2013;41: 580-637.

7. Greinacher A, Selleng K. Thrombocytopenia in the intensive care unit. Hematology Am SocHematolEduc Program. 2010;2010:135-43.

8. Drews RE, Weinber SE. Thrombocytopenic disorders in critically ill patients. Am J RespirCrit Care Med 2000;162:347-351.

9. Drews RE. Critical issues in hematology : anemia, thrombocytopenia, coagulopathy, and blood product transfusions in critically ill patients. Clin Chest Med. 2003;24:607-622.

10. Vanderscheren S, De Weerdt A, Malbrain M, et al. Thrombocytopenia and prognosis in intensive care. Crit Care Med 2000;28:1871-1876.

11. Strauss R, Wehler K, et al. Thrombocytopenia in patients in the medical intensive care unit: bleeding prevalence, transfusion requirements, and outcome. Crit Care Med 2002;30:1765-1771.

12. Akea S, Haji-Michael P, de Menodonca A, et al. Time course of platelet counts in critically ill patients. Crit Care Med 2002;30:753-756.

13. Stephan F, Hollande J, Richad O, et al . Thrombocytopenia in a surgical ICU. Chest 1999;115:1363-1370.

14. Brogly N, Devos P, Boussekey N, et al. Impact of thrombocytopenia on outcome of patients admitted to ICU for severe community-acquired pneumonia. J Infect 2007;55:136-140.

15. Baughman RP, Lower EE, Flessa HC, et al. Thrombocytopenia in the intensive care unit. Chest 1993;104:1243-1247.

16. Vandijck DM, Blot SI, De Waele JJ, et al. Thrombocytopenia and outcome in critically ill patients with bloodstream infection. Heart Lung 2010;39:21-26

17. Cowther MA, Cook DJ, Meade Mo et al. Thrombocytopenia in medicalsurgical critically ill patients: prevalence, incidence, and risk factors. J Crit Care 2005;20:348-353.

18. Rice TW, Wheeler AP. Coagulopathy in the critically ill patients. Part 1: Platelet disorders. Chest. 2009;136:1622-30.

Copyright: (c) the author(s), publisher. Academia Anesthesiologica Internationalis an Official Publication of "Society for Health Care \& Research Development". It is an open-access article distributed under the terms of the Creative Commons Attribution Non-Commercial License, which permits unrestricted non-commercial use, distribution, and reproduction in any medium, provided the original work is properly cited.

How to cite this article: Patni M, Pratap U, Sarawgi R, Gupta R.Association of Platelet Counts with Outcome of ICU Stay.Acad. Anesthesiol. Int. 2019;4(2):61-63.

DOI: dx.doi.org/10.21276/aan.2019.4.2.16

Source of Support: Nil, Conflict of Interest: None declared. 